\title{
Posisi Ibu Hamil Memengaruhi Akurasi Pengukuran Kesejahteraan Janin
}

\author{
Minarti ${ }^{\star}$, Risnawati \\ D-III Kebidanan, Politeknik Baubau \\ *Email korespondensi: minartimili11@gmail.com
}

\begin{abstract}
Article Info
ABSTRACT

Article history:

Submitted: 2020-06-10

Accepted: 2020-08-31

Published: 2020-09-6

Keywords:

Mother's position, fetal heart rate, pregnant;

During pregnancy, the fetal heart rate is a picture of the well-being of the fetus in the womb. The mother's position affects the results of the assessment when taking measurements of the fetal heart rate. The purpose of this study is to determine the accuracy of the measurement of fetal well-being based on the position of pregnant women. This type of research is analytic observational in Wajo Health Center, Katobengke Health Center, and Sulaa Health Center, from April - August 2019. The population in this study were all pregnant women registered in the KIA book. The research sample consisted of 60 respondents using inclusion criteria. The data analysis uses univariate analysis. The results showed there were differences in the value of the fetal heart rate measurements for each position. The average value (min-max) of DJJ measurement with the lying position (supine) 128-158 times per-minute, mean value 138.81 times per-minute; sitting position 124-158 times per-minute, mean value 143.41 times per-minute; standing position 126-159 times per-minute, mean value 145.58 times per minute. In a sitting and lying position, the resulting heart rate is in the normal range of 120-140 times per-minute; in a standing position, the heart rate obtained 150-160 times per-minute has the potential for tachycardia. The conclusion of this study is that the position of pregnant women affects the results of fetal heart rate measurement and the good position of the FHR measurement when lying on her back.
\end{abstract}

\section{ABSTRAK}

Kata kunci:

Posisi ibu, DJJ, Hamil;
Selama kehamilan, detak jantung janin adalah gambaran kesejahteraan janin di dalam rahim. Posisi ibu memengaruhi hasil penilaian saat melakukan pengukuran denyut jantung janin. Tujuan dari penelitian ini adalah untuk menentukan keakuratan pengukuran kesejahteraan janin berdasarkan posisi ibu hamil. Jenis penelitian ini adalah observasional analitik di Puskesmas Wajo, Puskesmas Katobengke, dan Puskesmas Sulaa, pada bulan April - Agustus 2019. Populasi dalam penelitian ini adalah semua ibu hamil yang terdaftar di buku KIA. Sampel penelitian berjumlah 60 responden menggunakan kriteria inklusi. Analisis data menggunakan analisis univariat. Hasil penelitian menunjukkan ada perbedaan nilai pengukuran denyut jantung janin untuk setiap posisi. Rerata nilai pengukuran DJJ dengan posisi berbaring (terlentang) antara $128-158 \mathrm{x} /$ menit, nilai mean $138,81 \mathrm{x} /$ menit; posisi duduk antara 124-158 x/menit, nilai mean 143,41; posisi berdiri antara 126-159 $\mathrm{x} /$ menit, nilai mean $145,58 \mathrm{x} /$ menit. Dalam posisi duduk dan berbaring, detak jantung yang dihasilkan berada dalam kisaran normal 120-140 kali/menit; dalam posisi berdiri, detak jantung yang diperoleh 150-160 kali/menit memiliki potensi untuk takikardia. Kesimpulan dari penelitian ini adalah posisi ibu hamil mempengaruhi hasil pengukuran denyut jantung janin dan posisi baik pengukuran DJJ saat berbaring terlentang. 


\section{PENDAHULUAN}

Secara global 2,5 juta anak meninggal pada bulan pertama kehidupan di tahun 2018. Ada sekitar 7.000 kematian bayi baru lahir setiap hari, yang merupakan $47 \%$ dari semua kematian anak di bawah usia 5 tahun, naik dari 40\% pada tahun 1990. Hampir sama jumlah bayi lahir mati (tahun 2015). ${ }^{1}$ Angka Kematian Bayi menurut Sustainanble Depelovment Goals (SDGs) tahun 2015 berjumlah 40 per 1000 kelahiran hidup dan masih menempati peringkat ke-4 tertinggi kematian bayi se-ASEAN. Angka kematian bayi (AKB) adalah jumlah kematian bayi dalam usia 28 hari pertama kehidupan per 1.000 kelahiran hidup. ${ }^{2}$ Cara untuk mengurangi kematian perinatal yang disebabkan oleh komplikasi yang terjadi pada janin di dalam rahim adalah dengan pemantauan kesejahteraan janin melalui pemeriksaan denyut jantung janin. ${ }^{3}$

Frekuensi denyut jantung janin pada usia 25 minggu adalah $150 \mathrm{x} /$ menit $^{3}$, sedangkan saat aterm 110-150x/menit. ${ }^{4}$ Nilai normal denyut jantung janin antara 120160 kali permenit. ${ }^{3}$ Denyut jantung janin juga dapat mengalami kelainan. Kelainan denyut jantung janin ada 2 yaitu : 1 . Takhikardi, terjadi apabila denyut jantung $>160$ denyut per menit. 2. Bradikardi, terjadi apabila denyut jantung $<120$ denyut per menit. ${ }^{5}$

Denyut jantung janin dasar menurun tajam seiring peningkatan usia gestasi sebagai akibat maturnya tonus parasimpatis. Pemeriksaan denyut jantung janin diukur 1 menit penuh. ${ }^{4}$ Keterlambatan pendiagnosaan pada janin dapat berisiko fatal pada janin, seperti kegagalan dalam perkembangan (cacat) hingga kematian pada janin. ${ }^{6}$ Hasil riset menyatakan $25 \%$ - $40 \%$ kematian bayi salah satu penyebabnya adalah janin yang hiperaktif. Gerakan janin yang berlebihan - apalagi hanya pada satu arah sajabisa mengakibatkan tali pusat yang menghubungkan ibu dengan janin terpelintir. Akibatnya, pembuluh darah yang mengalirkan suplai oksigen maupun nutrisi melalui plasenta ke janin akan tersumbat.

Secara umum mekanisme pengaturan denyut jantung janin (DJJ) diatur oleh banyak faktor, antara lain: sistem saraf simpatis, sistem saraf parasimpatis, baroresepter, kemoreseptor, susunan saraf pusat, simtem pengaturan hormonal dan sistem kompleks proprioseptor. ${ }^{7}$ Selain itu, denyut jantung janin dipengaruhi posisi ibu, aktivitas uterus, dan umur kehamilan ibu yang diakibatkan keseimbangan kematangan saraf simpatis dan parasimpatis, stress janin dan kecemasan yang dirasakan oleh ibu hamil. ${ }^{8}$ Hasil penelitian menunjukkan ada perbedaan yang signifikan antara frekuensi denyut jantung janin pada ibu hamil primigravida dengan ibu hamil multigravida dan pada kehamilan di trimester 2 dan trimester $3 .^{9}$

Jumlah kematian neonatal yang dilaporkan di Dinas Kesehatan Kabupaten /Kota di Sulawesi Tenggara mengalami fluktuatif, yaitu pada tahun 2012 sebanyak 484 kasus atau 16 per 1.000 kelahiran hidup, menurun pada tahun 2013 sebanyak 390 kasus atau 12 per 1.000 kelahiran hidup. Untuk tahun 2014 meningkat kembali 427 kasus atau 13 per 1.000 kelahiran hidup dan pada tahun 2015 menurun lagi menjadi 406 kasus atau 8 per 1.000 kelahiran hidup serta menurun kembali pada tahun 2016 sebanyak 332 kasus atau 7 per 1.000 kelahiran hidup. ${ }^{10-14}$ Angka kematian bayi di Kota Baubau 11-12 kasus atau 2 per 1.000 kelahiran hidup. Meskipun naik turun, secara umum jumlah kematian neonatal per tahunnya di Sulawesi Tenggara masih relatif tinggi. Namun jika merujuk pada target Renstra Kemenkes tahun 2016 sebesar $80 \%$, capaian tersebut masih jauh di bawah target, sehingga masih diperlukan upaya berkesinambungan dari berbagai sisi untuk mempercepat peningkatan cakupan penanganan komplikasi neonatal, baik dari segi tenaga dalam bentuk peningkatan kompetensi tenaga kesehatan, peningkatan fasilitas, sarana dan prasarana, maupun dari segi pembiayaan, sehingga diharapkan dapat menekan jumlah kematian neonatal di Sulawesi Tenggara. ${ }^{14}$ 
Denyut jantung janin merupakan suatu gambaran untuk mengukur kesejahteraan janin dalam rahim. Memahami lebih jauh faktor yang mempengaruhi denyut jantung janin adalah posisi ibu selama melakukan pengukuran. Posisi ibu mempengaruhi hasil pengukuran saat melakukan pemeriksaan denyut jantung janin. Namun, pemeriksaan denyut jantung janin yang dilakukan selama masih terpaku hanya dengan posisi ibu terlentang (baring). Tujuan dari penelitian ini adalah untuk menentukan keakuratan pengukuran kesejahteraan janin berdasarkan posisi ibu hamil sebagai alternatif pemeriksaan. Oleh karena itu, dalam penelitian ini peneliti melakukan penelitian tentang pengaruh posisi ibu hamil terhadap akurasi pengukuran kesejahteraan janin.

\section{METODE PENELITIAN}

Jenis penelitian yang digunakan adalah observasional analitik melakukan perbandingan secara langsung terhadap objek yang diteliti, dengan melakukan pemeriksaan denyut jantung janin (DJJ) pada ibu hamil dengan 3 (tiga) posisi: berdiri, duduk dan posisi baring terlentang di Puskesmas Wajo, Puskesmas Katobengke dan Puskesmas Sulaa, yang dilaksanakan dari April sampai Agustus 2019. Populasi adalah seluruh ibu hamil yang terdaftar dan memeriksakan diri. Sampel sebanyak 60 responden dengan kriteria usia kehamilan 20 - 39 minggu dan tidak memiliki riwayat penyakit jantung. Tahap Pertama (i) skrining sampel, (ii) intervensi awal untuk pengumpulan data awal (iii) penentuan waktu intervensi. Tahap Kedua intervensi pemeriksaan DJJ masing-masing ibu hamil dengan (i) posisi baring (ii) posisi duduk dan (iii) berdiri, setiap minggu (3 kali) pengukuran selama 3 minggu. Tahap Ketiga perbandingan akurasi pengukuran djj dengan (i) posisi baring terlentang (ii) posisi duduk dan (iii) berdiri. Analisis univariat untuk mengetahui karakteristik dan gambaran perbandingan hasil pemeriksaan DJJ pada posisi baring (terlentang), duduk dan posisi berdiri.

\section{HASIL PENELITIAN}

Berdasarkan hasil pengumpulan data, maka hasil penelitian dapat disajikan sebagai berikut:

Tabel 1. Karakteristik Umum Responden Ibu Hamil di Puskesmas Katobengke, Puskesmas Sulaa, dan Puskesmas Wajo

\begin{tabular}{lcc}
\hline Karakteristik Responden & Jumlah & Persentase (\%) \\
\hline Usia Kehamilan & & \\
$20-30$ minggu & 38 & 63,3 \\
31-42 minggu & 22 & 36,7 \\
Berat Badan & & \\
$40-50 \mathrm{~kg}$ & 10 & 16,7 \\
$51-60 \mathrm{~kg}$ & 36 & 60,0 \\
$61-70 \mathrm{~kg}$ & 9 & 15,0 \\
$\geq 71 \mathrm{~kg}$ & 5 & 8,3 \\
Paritas & & \\
1 & 22 & 36,0 \\
$2-5$ & 38 & 64,0 \\
\hline
\end{tabular}

Sumber : Data primer, 2019

Karakteristik responden berdasarkan usia kehamilan adalah 38 responden $(63,3 \%)$ pada kelompok umur $20-30$ minggu dan 22 responden $(36,7 \%)$ pada usia kehamilan 21-42 minggu.

Karakteristik responden berdasarkan berat badan yaitu sebagian besar 
memiliki massa $51-60 \mathrm{~kg}$ sebanyak 36 responden (60\%) dan setidaknya pada kelompok berat lebih dari 71 kilogram yaitu sebanyak lima responden (8,3\%).

Karakteristik responden berdasarkan jumlah paritas yaitu setidaknya satu memiliki paritas 22 responden (36\%), dan mayoritas memiliki paritas 2-5 yaitu sebanyak 38 responden $(63,3 \%)$.

Tabel 2. Distribusi Frekuensi Pengukuran Kesejahteraan Janin dengan Posisi Duduk, Posisi Berdiri dan Posisi Baring (Terlentang) minggu I

\begin{tabular}{|c|c|c|c|c|c|c|}
\hline \multirow{3}{*}{ DJJ } & \multicolumn{6}{|c|}{ Posisi } \\
\hline & \multicolumn{2}{|c|}{ Baring } & \multicolumn{2}{|c|}{ Duduk } & \multicolumn{2}{|c|}{ Berdiri } \\
\hline & $\mathbf{n}$ & $\%$ & $\mathbf{n}$ & $\%$ & $\mathbf{n}$ & $\%$ \\
\hline $120-130 \mathrm{x} / \mathrm{m}$ & 16 & 26,7 & 6 & 10,0 & 2 & 3,3 \\
\hline $131-140 \mathrm{x} / \mathrm{m}$ & 15 & 25,0 & 19 & 31,7 & 15 & 25,0 \\
\hline $141-150 \mathrm{x} / \mathrm{m}$ & 25 & 41,7 & 24 & 40,0 & 27 & 45,0 \\
\hline $151-160 \mathrm{x} / \mathrm{m}$ & 4 & 6,7 & 11 & 18,3 & 16 & 26,7 \\
\hline Total & 60 & 100,0 & 60 & 100,0 & 60 & 100,0 \\
\hline
\end{tabular}

Berdasarkan tabel 2. pada pengukuran denyut jantung janin minggu pertama menunjukkan presentase terbanyak dan terkecil ada pada posisi berdiri yaitu dengan durasi 141-150x/menit dan 120-130x/menit.

Tabel 3. Distribusi Frekuensi Pengukuran Kesejahteraan Janin dengan posisi Duduk, Posisi Berdiri dan Posisi Baring (Terlentang) minggu II

\begin{tabular}{lrrrrrr}
\hline \multirow{2}{*}{ DJJ } & \multicolumn{9}{c}{ Posisi } \\
\cline { 2 - 7 } & \multicolumn{2}{c}{ Baring } & \multicolumn{2}{c}{ Duduk } & \multicolumn{2}{c}{ Berdiri } \\
\cline { 2 - 7 } & $\mathbf{n}$ & \multicolumn{1}{c}{$\%$} & \multicolumn{1}{c}{$\mathbf{n}$} & $\%$ & \multicolumn{1}{c}{$\mathbf{n}$} & \multicolumn{1}{c}{$\%$} \\
\hline $120-130 \mathrm{x} / \mathrm{m}$ & 3 & 5,0 & 2 & 3,3 & 1 & 1,7 \\
$131-140 \mathrm{x} / \mathrm{m}$ & 42 & 70,0 & 16 & 26,7 & 11 & 18,3 \\
$141-150 \mathrm{x} / \mathrm{m}$ & 14 & 23,3 & 35 & 58,3 & 37 & 61,7 \\
$151-160 \mathrm{x} / \mathrm{m}$ & 1 & 1,7 & 7 & 11,7 & 11 & 18,3 \\
\hline Total & 60 & 100 & 60 & 100 & 60 & 100 \\
\hline Sumber: Data primer, 2019 & & & & &
\end{tabular}

Berdasarkan tabel 3. pada pengukuran denyut jantung janin minggu kedua menunjukkan presentase terbanyak ada pada posisi berdiri dengan jumlah sebanyak 37 orang pada durasi 141-150x/menit dan terkecil ada pada posisi baring dengan jumlah sebanyak 1 orang pada durasi 151-160x/menit.

Tabel 4. Distribusi Frekuensi Pengukuran Kesejahteraan Janin dengan posisi Duduk, Posisi Berdiri dan Posisi Baring (Terlentang) minggu III

\begin{tabular}{lrrrrrr}
\hline \multirow{2}{*}{ DJJ } & \multicolumn{9}{c}{ Posisi } \\
& \multicolumn{2}{c}{ Baring } & \multicolumn{2}{c}{ Duduk } & \multicolumn{2}{c}{ Berdiri } \\
\cline { 2 - 7 } & $\mathbf{n}$ & \multicolumn{1}{c}{$\%$} & \multicolumn{1}{c}{$\mathbf{n}$} & \multicolumn{1}{c}{$\%$} & \multicolumn{1}{c}{ n } & \multicolumn{1}{c}{} \\
\hline $120-130 \mathrm{x} / \mathrm{m}$ & 6 & 10,0 & 3 & 5,0 & 1 & 1,7 \\
$131-140 \mathrm{x} / \mathrm{m}$ & 28 & 46,7 & 19 & 31,7 & 13 & 21,7 \\
$141-150 \mathrm{x} / \mathrm{m}$ & 23 & 38,3 & 32 & 53,3 & 32 & 53,3 \\
$151-160 \mathrm{x} / \mathrm{m}$ & 3 & 5,0 & 6 & 10,0 & 14 & 23,3 \\
\hline Total & 60 & 100,0 & 60 & 100,0 & 60 & 100,0 \\
Sumber: Data primer, 2019 & & & &
\end{tabular}

Berdasarkan tabel 4. pada pengukuran denyut jantung janin minggu ketiga menunjukkan presentase terbanyak ada pada posisi duduk dan berdiri dengan 
jumlah sebanyak 32 orang $(53,3 \%)$ pada durasi $141-150 x /$ menit dan terkecil ada pada posisi berdiri dengan jumlah sebanyak 1 orang pada durasi 120130x/menit.

Tabel 5. Rerata Nilai Penggukuran DJJ dengan Posisi Baring, Posisi Duduk dan Posisi Berdiri

\begin{tabular}{lcc}
\hline Posisi Pengukuran & Nilai Min-Max & Mean \\
\hline Baring & $128-158$ & 138,81 \\
Duduk & $124-158$ & 143,41 \\
Berdiri & $126-159$ & 145,58 \\
\hline
\end{tabular}

Sumber: Data primer, 2019

Berdasarkan tabel 5. hasil yang diperoleh dari pengukuran denyut jantung janin dengan posisi duduk dan posisi berdiri memiliki nilai dalam batas normal dengan perbedaan yang tidak signifikan yakni sebesar 143,41 dan 145,58. Berbeda dengan rerata yang diperoleh dari hasil pengukuran DJJ pada posisi baring, diperoleh nilai rerata sebesar 138,81. Pada posisi baring terlentang merupakan posisi yang sangat baik untuk pengukuran DJJ. Hal ini dikarenakan secara anatomis letak jantung janin dan ibu berada pada posisi yang sama karena terletak pada bidang datar yang sama.

\section{PEMBAHASAN}

Pemeriksaan DJJ dilakukan sebagai acuan untuk mengetahui kesehatan ibu dan perkembangan janin khususnya saat dalam rahim. Frekuensi denyut jantung janin yang normal adalah 120-160 x/menit. ${ }^{7}$ Berdasarkan penelitian yang telah dilakukan, hasil pengukuran frekuensi denyut jantung janin (DJJ) berdasarkan posisi ibu ditiap minggunya menunjukkan bahwa posisi berdiri cenderung menunjukkan rentang DJJ yang lebih tinggi dibanding dengan posisi duduk dan berbaring yaitu sebesar 151-160 $\mathrm{x} /$ menit. Dari hasil yang diperoleh sejalan dengan penelitian yang dilakukan oleh Wahyuni yakni melakukan pengukuran DJJ pada 14 responden yang diberikan perlakukan berjalan kaki yang kemudian diukur DJJ pada saat berdiri. Hasil penelitiann menunjukkan frekuensi DJJ sebesar 148-160x/menit. ${ }^{15}$

Teori yang dikemukakan oleh Widmaier, et al, 2008 apabila seseorang dalam posisi berdiri, tekanan intravascular di semua tempat menjadi sama dengan tekanan yang dihasilkan oleh kontraksi jantung. Ditambah dengan adanya tekanan tambahan dengan berat kolom darah dari jantung ke titik pengukuran. ${ }^{16}$ Peningkatan tekanan akibat gravitasi juga mempengaruhi volume sirkulasi darah efektif melalui beberapa cara, misalnya peningkatan tekanan hidrostatik yang terjadi dikaki ketika seseorang berdiri akan mendorong keluar dinding vena sehingga menyebabkan distensi, yang hasilnya menyebabkan pengumpulan darah di pembuluh vena. ${ }^{17}$

Berdasarkan teori tersebut diatas maka sangat mungkin DJJ mengalami peningkatan karena janin kurang memperoleh pasokan darah ke jaringan plasenta. Dengan demikian janin tidak memiliki daya yang cukup kuat untuk meningkatkan aliran darah umbilicus yang akhirnya akan menekan/meningkatkan curah jantung. ${ }^{15}$ bila keadaan ini terus berlanjut maka dapat mengganggu kesejahteraan janin yaitu dapat menyebabkan terjadinya takikardi.

Hasil pemeriksaan DJJ yang dilakukan pada saat ibu pada posisi duduk dan berbaring cenderung menunjukkan hasil yang relatif normal yaitu pada kisaran 130140x/menit. Hal ini disebabkan karena pada saat posisi duduk maupun berbaring, pusat gravitasi berada pada bagian anterior iscia dan sekitar $25 \%$ berat badan ditransmisikan ke bawah melalui ekstremitas bawah sehingga anggota tubuh dalam 
keadaan rileks. Pada kondisi tersebut sangat memungkinkan sirkulasi darah yang mengalir dari plasenta ke janin melalui vena umbilicus akan lebih lancar sehingga frekuensi denyut jantung janin berada pada kisaran normal 120-160 x/menit.

Pada saat ibu berada pada posisi yang nyaman dan rileks, kadar persediaan oksigen dari ibu ke janin akan lebih lancar sehingga dapat memberikan dampak yang baik pada denyut jantung janin, Selain itu perlu adanya gerakan-gerakan yang dapat memberikan kenyamanan pada ibu misalnya ibu melakukan senam hamil.

Saat ibu berada pada posisi berdiri, denyut jantung yang diperoleh menunjukkan nilai 150-160 kali/menit. Walaupun hasil pengukuran tersebut masih dalam batas normal namun berpotensi terjadinya takikardi. Selain itu, dari hasil intervensi melakukan pengukuran DJJ dengan posisi berdiri dan duduk kemudahan yang diperoleh adalah pemeriksa dapat melakukan pemeriksaan DJJ dengan lebih mudah dan kapan saja. Namun pemeriksaan DJJ dengan posisi duduk dan berdiri memerlukan waktu yang lebih banyak untuk penentuan letak serta detak jantung janin terdengar kurang jelas bahkan hilang timbul dalam proses pengukuran.

Pengukuran denyut jantung janin dengan berbagai posisi yakni posisi baring (terlentang), posisi duduk dan posisi berdiri menunjukkan ada perbedaan nilai yang dihasilkan. Namun, sama-sama dapat dilakukan oleh provider (bidan) karena perbedaan nilai yang dihasilkan masih dalam batas normal. Perbedaan posisi pengukuran ini sebenarnya dapat menjadi variasi bila terjadi keadaan dimana banyaknya jumlah pasien yang berkunjung untuk pemeriksaan dengan jumlah bidan yang terbatas atau ruangan yang tidak memadai sehingga ada kemudahan dalam melakukan tindakan tanpa menyepelehkan hak pasien. Pada posisi baring terlentang merupakan posisi yang sangat baik untuk pengukuran DJJ. Hal ini dikarenakan secara anatomis letak jantung janin dan ibu berada pada posisi yang sama karena terletak pada bidang datar yang sama.

\section{SIMPULAN DAN SARAN}

Penelitian ini menyimpulkan rerata nilai pengukuran DJJ posisi berbaring (terlentang) adalah 138,81 x/menit, rerata pengukuran DJJ posisi duduk adalah 143,41 x/menit, dan rerata pengukuran DJJ posisi berdiri 145,58 x/menit. Posisi yang baik untuk mengukur DJJ adalah berbaring. Penelitian ini menyarankan pada bidan untuk memperhatikan posisi ibu dalam mengukur denyut jantung janin.

\section{UCAPAN TERIMA KASIH}

Peneliti mengucapkan terima kasih kepada Kemenristek-Brin yang telah mendanai penelitian ini serta kepada para pimpinan Puskesmas Wajo, Puskesmas Katobengke, dan Puskesmas Sulaa dan seluruh pegawai atas kesempatan dan motivasi yang diberikan selama meneliti.

\section{DAFTAR PUSTAKA}

1. World Health Organization. Newborns: Reducing Mortality [Internet]. 2019. Available from: https://www.who.int/news-room/fact-sheets/detail/newborns-reducing-mortality

2. Kementerian Kesehatan R.I. Dukung Ibu Bekerja Beri ASI Eksklusif [Internet]. Kementerian Kesehatan R.I. 2015.2 Available from: https://www.kemkes.go.id/article/view/15091400003/dukung-ibu-bekerja-beri-asieksklusif.html

3. Bobak IM, Wijayarini MA, Anugerah PI, Jensen MD, Lowdermilk DL. Buku Ajar Keperawatan Maternitas. Jakarta: EGC; 2005.

4. Gondo HK, Ewardewa TGA. Kardiotokografi Mengerti dan Memahami Pemantauan Denyut Jantung Janin [Internet]. Suyono J, editor. Jakarta: EGC; 2010. Available from: 
https://onesearch.id/Record/IOS13415.INLIS000000000041993

5. Prawirohardjo S. Ilmu Kebidanan. Jakarta: Yayasan Bina Pustaka Sarwono Prawirohardjo; 2008.

6. Sinaga AD, Purwarini J, Anggraeni LD. The Experiences of Mothers with Intrauterine Fetal Death/Demise (IUFD) in Indonesia. Nurse Media J Nurs. 2020;10(1):86-95.

7. Endjun JJ, Santana S, Resistantie N. Standarisasi Pemantauan Kesejahteraan Janin [Internet]. Jakarta; 2015. Available https://studylibid.com/doc/528152/standarisasi-pemantauan-kesejahteraan-janin

8. Manuaba IBG. IImu Kebidanan, Penyakit Kandungan, dan Keluarga Berencana. Jakarta: EGC; 2010.

9. Chabibah N, Laela EN. Perbedaan Frekuensi Denyut Jantung Janin Berdasarkan Paritas dan Usia Kehamilan. Siklus J Res Midwifery Politek Tegal [Internet]. 2017 Feb 2;6(1):195-8. Available https://ejournal.poltektegal.ac.id/index.php/siklus/article/view/471

10. Dinas Kesehatan Propinsi Sulawesi Tenggara. Profil Kesehatan Sulawesi Tenggara Tahun 2012. Kendari: Dinas Kesehatan Propinsi Sulawesi Tenggara; 2013.

11. Dinas Kesehatan Propinsi Sulawesi Tenggara. Profil Kesehatan Sulawesi Tenggara Tahun 2013. Kendari: Dinas Kesehatan Propinsi Sulawesi Tenggara; 2014.

12. Dinas Kesehatan Propinsi Sulawesi Tenggara. Profil Kesehatan Sulawesi Tenggara Tahun 2014. Kendari: Dinas Kesehatan Propinsi Sulawesi Tenggara; 2015.

13. Dinas Kesehatan Propinsi Sulawesi Tenggara. Profil Kesehatan Sulawesi Tenggara Tahun 2015. Kendari: Dinas Kesehatan Propinsi Sulawesi Tenggara; 2016.

14. Dinas Kesehatan Propinsi Sulawesi Tenggara. Profil Kesehatan Sulawesi Tenggara Tahun 2016. Kendari: Dinas Kesehatan Propinsi Sulawesi Tenggara; 2017.

15. Wahyuni C. Candra Wahyuni. J Qual Women's Heal [Internet]. 2018;1(1). Available from: https://jqwh.org/index.php/JQWH/article/view/6

16. Widmaier E, Raff H, Strang K. Vander's Human Physiology: The Mechanisms of Body Function. 12th ed. New York: McGraw-Hill Education; 2008.

17. Manembu M, Rumampuk J, Danes VR. Pengaruh Posisi Duduk Dan Berdiri Terhadap Tekanan Darah Sistolik Dan Diastolik Pada Pegawai Negeri Sipil Kabupaten Minahasa. J e-Biomedik [Internet]. 2015 Sep 11;3(3). Available from: https://ejournal.unsrat.ac.id/index.php/ebiomedik/article/view/10150 